\title{
THBS2, a microRNA-744-5p target, modulates MMP9 expression through CUX1 in pancreatic neuroendocrine tumors
}

\author{
HENG JIAO $^{1 *}$, LINGXIAO ZENG $^{1 *}$, JIANPENG ZHANG $^{2}$, SHENGSHENG YANG $^{2}$ and WENHUI LOU ${ }^{1}$ \\ ${ }^{1}$ Department of General Surgery, Zhongshan Hospital, Fudan University, Shanghai 200032; ${ }^{2}$ Department of Biochemistry and \\ Molecular Biology, College of Basic Medical Sciences, Second Military Medical University, Shanghai 200433, P.R. China
}

Received March 3, 2019; Accepted September 20, 2019

DOI: $10.3892 / \mathrm{ol} .2020 .11273$

\begin{abstract}
The underlying molecular mechanisms of pancreatic neuroendocrine tumor ( $\mathrm{pNET}$ ) development have not yet been clearly identified. The present study revealed that thrombospondin 2 (THBS2) was downregulated in pNET tissues and cells. Forced expression of THBS2 inhibited the proliferation and migration of pNET cells in vitro. MicroRNA(miR)-744-5p was indicated to be a direct regulator of THBS2. Upregulation of miR-744-5p potentially caused THBS2 repression. Furthermore, THBS2 inhibited the production of matrix metalloproteinase (MMP) MMP9 through suppressing the transcriptional activity of CUT-like homeobox 1 (CUX1). CUX1 and MMP9 mediated the effect of THBS 2 on pNET proliferation and migration, respectively. The results of the present study revealed a mechanistic role for THBS2 in pNET proliferation and migration, indicating that THBS2 was downregulated by miR-744-5p and further affected the CUX1/MMP9 cascade, which promoted the development of pNET.
\end{abstract}

\section{Introduction}

Pancreatic neuroendocrine tumor (pNET), a group of endocrine tumors originates from the islets of the Langerhans in the pancreas, accounts for $1-2 \%$ of all pancreatic neoplasms $(1,2)$. pNET are classified into functional (including insulinoma,

Correspondence to: Dr Shengsheng Yang, Department of Biochemistry and Molecular Biology, College of Basic Medical Sciences, Second Military Medical University, 800 Xiangyin Road, Shanghai 200433, P.R. China

E-mail: shengshengyang@126.com

Dr Wenhui Lou, Department of General Surgery, Zhongshan Hospital, Fudan University, 180 Fenglin Road, Shanghai 200032, P.R. China

E-mail:wenhuiloush@126.com

${ }^{*}$ Contributed equally

Key words: pancreatic neuroendocrine tumor, thrombospondin 2, matrix metalloprotease 9, microRNA-744-5p, CUT-like homeobox 1 gastrinoma and rare functional pNET) and non-functional types according to their capacity to stimulate hormonal hypersecretion, as well as the clinical presentation itself $(1,2)$. Chromosomal alterations cause pNET through the loss of tumor suppressor genes, such as MEN1, VHL and p53, or gain of oncogenes, such as CCND1 (3). Mutations induce precursor lesions, such as diffuse endocrine cell hyperplasia, dysplasia and microadenoma, which transform into clinical pNETs accompanied by an accumulation of additional mutations $(2,4)$. The annual incidence of pNET has increased in the past few years, from 1.4 to 3.0 per million between 1973 and 2004, according to an analysis on the pNET cases the Surveillance, Epidemiology, and End Results database (1), and patients with unresectable or metastatic tumor tend to present with a poor prognosis (4). Thus, a better understanding of the molecular mechanisms that trigger and drive cancer progression is required in order to develop effective strategies for the treatment of pNET. Matrix metalloproteases (MMPs) have been extensively studied with regard to migration and invasion activity in cancer (5). MMP2 and MMP9, known as gelatinases, modulate degradation of the main component of basal membranes (collagen type IV) and induce metastasis (6). In pNET, MMP9 is associated with invasion activity of tumor cells and acts as a potent trigger of the angiogenic switch in mice models $(7,8)$.

Thrombospondins (THBSs) are a family of matricellular calcium binding glycoprotein that mediate cell-to-cell and cell-to-matrix interactions. Among the five members of the THBSs family, THBS1 and THBS2 are unique due to their type I repeats and antiangiogenic activities (9). THBS2 reportedly interacted with multiple cell surface receptors (LRP, CD36, CD47 and various integrins), growth factors (TGF- $\beta$ and FGF2), ECM proteins (decorin, HSPGs and fibronectin) and enzymes (MMPs, elastase and cathepsin G) $(10,11)$. LRP binds to THBS2 in the pericellular environment to modulate endocytosis and the lysosomal degradation of THBS2. Downregulation of THBS2 inhibits the formation of the THBS2-MMP2 complex, leading to decreased MMP2 recycling via LRP, which regulates tissue-transglutaminase and VEGF and affects collagen fibrillogenesis and angiogenesis (12). Through binding to CD36, THBS2 regulates a diverse range of activities including angiogenesis, apoptosis and metastasis $(13,14)$. THBS2 is an FGF2 ligand that can block FGF2 interaction with proangiogenic receptors, such as heparin or FGFR1 (15). THBS2 Hep1 peptide can also 
bind actin to alter cytoskeletal reorganization (16). THBS2 participates in the progression of multiple different types of cancer, but with paradoxical functions, for example, THBS2 inhibited tumor progression in cervical cancer, but promoted tumor progression in colorectal carcinoma, thyroid cancer, gastric cancer and hepatocellular carcinoma (13). Furthermore, the detailed function of THBS2 in pNET remains to be elucidated.

THBS trimer has been reported to inhibit the signaling of two members of the tethered ligand receptor family: The thrombin receptor and the trypsin receptor. For example, thrombospondin suppressed protease-activated receptor 2 (PAR2) via CD36 in human microvascular endothelial cells (17). Simultaneously, PAR2 promoted the DNA binding activity of CUT-like homeobox 1 (CUX1), a transcription factor that promoted the aggressiveness of pNET partly through MMP9 $(4,18)$. Thus, the aim of the present study was to examine whether THBS2 suppressed the transcription activity of CUX1 via MMP9. In the present study, it was revealed that THBS2 was significantly downregulated in pNET and modulated the proliferation and migration activity of pNET tumor cells. The present study also investigated the effect of THBS2 on the CUX1/MMP9 cascade and revealed that THBS2 regulated the expression of MMP9 through CUX1. Furthermore, microRNA(miR)-744-5p activated the Wnt/ $\beta$-catenin pathway and functioned as a diagnostic and prognostic biomarker in pancreatic cancer, according to previous reports (19). The present study also proved that THBS2 was a target of miR-744-5p in pNET.

\section{Materials and methods}

Patients and samples. A total of 10 cases of pNET specimens, which were histopathologically and clinically diagnosed, and resected between 10th May, 2017 and 10th November, 2017 at the Zhongshan Hospital of Fudan University (Shanghai, China), were investigated in the present study. The patients included five men and five women, aged between 45-84 years. pNET is a well-differentiated neuroendocrine tumor. They resemble normal endocrine cells, express neuroendocrine markers (chromogranin A and synaptophysin) and hormones (such as insulin, gastrin, vasoactive intestinal polypeptide, glucagon), have mild or moderate nuclear atypical changes, and have low mitotic numbers $[<2 / 10$ high power fields (HPF)]. pNET are classified into three grades, according to 2010 World Health Organization classification (20): Grade 1 where the number of mitotic figures in tumor cells is $<2 / 10$ $\mathrm{HPF}$, and/or Ki-67 positive index $<2 \%$; Grade 2 where the number of mitotic figures in tumor cells is between 2-20/10 HPF and/or Ki-67 positive index 3-20\%; and Grade 3 where the number of mitotic figure in tumor cells is $>20 / 10 \mathrm{HPF}$ and/or Ki-67 positive index $>20 \%$. The mitotic image requires at least $50 \mathrm{HPF}$, and the $\mathrm{Ki}-67$ positive index requires that the number of Ki-67 positive cells are calculated on the basis of 500 to 2,000 cells in the proliferative active region. The resected tissues were frozen and stored in liquid nitrogen. Paracancerous specimens were at least $2 \mathrm{~cm}$ away from tumor tissue. The present study was approved by Ethics Committee of the Zhongshan Hospital of Fudan University (Shanghai, China) and all the specimens were used for scientific research. All participants provided written informed consent prior to treatment. The clinical information of the specimens are summarized in Table I.

Cell culture. The pNET cell line BON-1, human kidney epithelial cell line 293 and human lung fibroblast CCL-153 were cultured in the DMEM medium (Gibco; Thermo Fisher Scientific, Inc.) supplemented with $10 \%$ fetal bovine serum (FBS) (HyClone; GE Healthcare Sciences). QGP-1 cells were maintained in RPMI-1640 medium (Gibco; Thermo Fisher Scientific, Inc.) supplemented with 10\% FBS. All cells were supplemented with $2 \mathrm{mM} \mathrm{L}$-glutamine, 100 units $/ \mathrm{ml}$ penicillin, and $100 \mu \mathrm{g} / \mathrm{ml}$ streptomycin (Invitrogen; Thermo Fisher Scientific, Inc.) and placed in a humidified chamber with $5 \% \mathrm{CO}_{2}$ at $37^{\circ} \mathrm{C}$. All the cells were purchased from Chinese Academy of Sciences, Shanghai Institutes for Biological Sciences. In the present study, a normal pancreas cell line corresponding to pNET cells was not used and therefore, 293 and CCL-153 cell lines were used instead, according to a previous study (21).

Cell transfection. The human THBS2 gene was cloned into pGV358 lentiviral vector (Shanghai GeneChem Co., Ltd.). The pGV358-THBS2 plasmid $(20 \mu \mathrm{g})$ was mixed with the Helper $1.0(15 \mu \mathrm{g})$ and Helper $2.0(10 \mu \mathrm{g})$ packaging helper plasmid in $1 \mathrm{ml}$ GeneChem transfection reagent (Shanghai GeneChem Co., Ltd.) and then added to the 293 cells in $10 \mathrm{~cm}$ cell culture dish. Supernatants were collected $48 \mathrm{~h}$ post-transfection and incubated with QGP-1 and BON-1 cells at $37^{\circ} \mathrm{C}$ for $24 \mathrm{~h}$. After 14 days of puromycin selection, THBS2 overexpressed (OE) and negative control (NC) cell lines were established. Lipofectamine $^{\circledast} 3000$ (Invitrogen; Thermo Fisher Scientific, Inc.) was used for transfection.

Reverse transcription-quantitative PCR (RT-qPCR). Total RNA was extracted from cells/tissues using TRIzol ${ }^{\circledR}$ reagent (Invitrogen; Thermo Fisher Scientific, Inc.). RT was performed using the PrimeScript RT reagent kit (Takara Bio, Inc.) for the mRNA (at $37^{\circ} \mathrm{C}$ for $15 \mathrm{~min}$ followed by inactivation at $85^{\circ} \mathrm{C}$ for $5 \mathrm{sec}$ ), and miScript II RT kit (Qiagen $\mathrm{GmbH}$ ) for miRNA (at $37^{\circ} \mathrm{C}$ for $60 \mathrm{~min}$ followed by inactivation at $95^{\circ} \mathrm{C}$ for $5 \mathrm{~min}$ ). RT-qPCR was performed using a SYBR Premix Ex Taq kit (Takara Bio, Inc.) and miScript PCR Starter kit (Qiagen $\mathrm{GmbH}$ ). GAPDH was selected as the reference gene for proteins and U6 was used as the internal control for miRNA. The qPCR conditions were used as follows: Initial denaturation at $95^{\circ} \mathrm{C}$ for $3 \mathrm{~min}$, followed by 40 cycles of $95^{\circ} \mathrm{C}$ for $5 \mathrm{sec}$ and $58^{\circ} \mathrm{C}$ for $30 \mathrm{sec}$. Relative gene expression was analyzed using the $2^{-\Delta \Delta C q}$ method (22) and normalized to the controls (GAPDH or U6).

Primer information: miR-744 forward, 5'-TGCGGGGCT AGGGCTAACAGCA-3' and the universal reverse primer, 5'-TGTCGTGGAGTCGGC-3'; U6 forward, 5'-CTCGCTTCG GCAGCACA-3' and reverse, 5'-AACGCTTCACGAATTTGC GT-3'; THBS2 forward, 5'-GACACGCTGGATCTCACC TAC-3' and reverse, 5'-GAAGCTGTCTATGAGGTCGCA-3'; CUX1 forward, 5'-GACGTGTTGCGCACTTAACG-3' and reverse, 5'-ACGACATAGATTGGGCTTAATGCT-3'; MMP9 forward, 5'-TTGACAGCGACAAGAAGTGG-3' and reverse, 5'-GCCATTCACGTCGTCCTTAT-3'; GAPDH forward, 
Table I. Sample descriptions.

\begin{tabular}{lclc}
\hline Record number & Specimen number & Pathological pattern & Pathological grading \\
\hline 80,6194 & A4 & NET & G2 \\
78,3988 & A5 & NET & G1 \\
78,2319 & A6 & NET & G1 \\
83,3221 & B1 & NET & G2 \\
81,9036 & B2 & NET & G1 \\
83,1295 & B3 & NET & G1 \\
89,1998 & B4 & NET & G2 \\
76,3270 & B6 & NET, Insulinoma & G1 \\
99,2946 & B9 & NET, Insulinoma & NET, Insulinoma \\
\hline
\end{tabular}

A, cancer and matching paracancerous specimen; B, cancer specimen; NET, neuroendocrine tumor; G, grading.

5'-TGCACCACCAACTGCTTAGC-3' and reverse, 5'-GGC ATGGACTGTGGTCATGAG-3'. All primers were purchased from Sangon Biotech Co., Ltd.).

Western blot analysis. The protein was extracted from pNET cells using RIPA lysis buffer (Beijing Solarbio Science and Technology Co., Ltd.) with $1 \mathrm{mM}$ phenylmethylsulfonyl fluoride (Beijing Solarbio Science and Technology Co., Ltd.) on ice and determined using a BCA protein assay kit (Bio-Rad Laboratorites, Inc.). A total of $1 \mathrm{mg}$ protein was separated via SDS-PAGE (12\% gel) and transferred to polyvinylidene difluoride (PVDF) membranes (EMD Millipore). The membranes were subsequently blocked with $5 \%$ skimmed milk powder at room temperature for $1 \mathrm{~h}$ and incubated with antibodies against THBS2 (cat. no. ab112543; 1:1,000; Abcam) and GAPDH (cat. no. 97166; 1:1,000; Cell Signaling Technology, Inc.) at $4^{\circ} \mathrm{C}$ overnight. The membranes were then incubated with a horseradish peroxidase labeled horse anti-mouse secondary antibodies (cat. no. 7076; 1:1,000; Cell Signaling Technology, Inc.) or a goat anti-rabbit secondary antibody (cat. no. ab7090; 1:10,000; Abcam) for $1 \mathrm{~h}$ at room temperature and Pierce ECL Substrate were used to visualize the target proteins.

MTT assay. Cell proliferation was assessed using a MTT Cell Proliferation kit (Roche Diagnostics). The cells $\left(4 \times 10^{3}\right.$ cells/well) were seeded into 96 -well plates and cultured at $37^{\circ} \mathrm{C}$. Upon reaching about $70 \%$ confluence, the cells were transfected and then incubated for 2, 3, 4 or 6 days. A total of $20 \mu \mathrm{l}$ MTT reagent $(5 \mathrm{mg} / \mathrm{ml})$ was added to each well for $4 \mathrm{~h}$ and then removed, after which $150 \mu \mathrm{l}$ DMSO was added to dissolve the formazan crystals. Finally, the absorbance at $570 \mathrm{~nm}$ was measured.

EdU assay. The EdU assay was performed using a Cell-Light EdU DNA Cell Proliferation kit (Guangzhou RiboBio). The cells $\left(1 \times 10^{4}\right)$ were cultured in 24 well plates at $37^{\circ} \mathrm{C}$ for $24 \mathrm{~h}$. After incubation with $50 \mu \mathrm{M} \mathrm{EdU}$ for $2 \mathrm{~h}$ at $37^{\circ} \mathrm{C}$, the cells were fixed with $4 \%$ paraformaldehyde for $30 \mathrm{~min}$ at $37^{\circ} \mathrm{C}$ and then neutralized by Glycine. After the cells were permeabilized by $0.5 \%$ TritonX-100 for $10 \mathrm{~min}$ at room temperature, Apollo Dye Solution was added to react with the EdU at room temperature for $30 \mathrm{~min}$. Nucleic acid was stained with Hoechst at room temperature for $5 \mathrm{~min}$. Images were captured with an inverted fluorescence microscope (Olympus) at x200 magnification and 5 fields of each well were randomly selected to obtain images.

Transwell assay. A total of $1 \times 10^{4}$ cells in $100 \mu 1$ low serum DMEM medium $(0.1 \%$ FBS $)$ were plated into the upper chamber, to ensure cell survival, while $600 \mu 1$ DMEM supplemented with $20 \%$ FBS was added to the lower chamber as a chemical attractant. The cells were incubated at $37^{\circ} \mathrm{C}$ for $24 \mathrm{~h}$, after which the cells on the upper surface of the filter were removed and the cells on the lower side of the filter were stained with $0.1 \%$ crystal violet at room temperature for $5 \mathrm{~min}$. The cells in five randomly selected fields were counted under an inverted light microscope (Olympus) at x100 magnification.

Bioinformatics analysis. GSE73338 (https://www.ncbi. nlm.nih.gov/geo/query/acc.cgi?acc $=$ GSE73338) and GSE43796 (https://www.ncbi.nlm.nih.gov/geo/query/acc. cgi?acc=GSE43796) from Gene Expression Omnibus (GEO) database (https://www.ncbi.nlm.nih.gov/geo/) was analyzed to identify differentially expressed genes in pNET. The online databases of TargetScan (http://www.targetscan.org/vert_72/), miRTarBase (http://mirtarbase.mbc.nctu.edu.tw/php/search. php), RegRNA2.0 (http://regrna2.mbc.nctu.edu.tw/detection. html) and RNA22 (https://cm.jefferson.edu/rna22/) were used to predict the putative binding miRNA and the miRNA response elements (MRE) of THBS2. The LinkedOmics databases (http://www.linkedomics.org/admin.php) was searched to identify miRNAs that were negatively correlated with THBS2 in pancreas-adenocarcinoma-other subtype, which were subsequently aligned them with the targeted miRNAs that were predicted by TargetScan, miRTarBase and RegRNA2.0 to obtain the potential targets.

Luciferase reporter assay. The 293 cells in 96 well plates $\left(4 \times 10^{3}\right.$ cells/well) were cotransfected with THBS 2 or THBS2-MRE mutant reporter constructs and miR-744 mimics (5'-TGCGGGGCTAGGGCTAACAGCA-3') or mi-NC (5'-UUCUCCGAACGUGUCACGUTT-3') (Sangon Biotech Co., Ltd.) using Lipofectamine ${ }^{\circledR} 3000$ (Invitrogen; 
Thermo Fisher Scientific, Inc.). After $48 \mathrm{~h}$ of incubation, luciferase activity was measured by dual-luciferase reporter assay system (Promega Corporation) according to the manufacturer's protocol. The experiments were performed in triplicate and the relative luciferase activity was normalized to the Renilla luciferase activity.

Adhered pNET cells were cotransfected with the reporter constructs with or without MMP9 promoter (Beijing Haichuang Keye Biotechnology Co., Ltd.) and the vectors (pCDH-CMVMCS-EF1-CopGFP-T2A-puro) with or without CUX1 coding sequences (Beijing Haichuang Keye Biotechnology Co., Ltd.). The luciferase activity was determined after $48 \mathrm{~h}$ of incubation. Cells transfected with the MMP9 promoter reporter and the overexpression vector plasmid (pCDH-CMV-MCS-EF1-C opGFP-T2A-puro) were used as controls.

Immunohistochemistry (IHC) assay. Fresh samples from patients with pNET were cut into $1.5 \times 1.5 \times 0.2 \mathrm{~cm}^{3}$ sections and fixed with $10 \%$ neutral formalin at room temperature for $24 \mathrm{~h}$. The specimens were dehydrated by a graded series of ethanol solutions $(80,90,95$ and $100 \%)$, the ethanol was gradually removed using 1:1 ethanol and dimethlbenzene mixture followed by $100 \%$ dimethlbenzene, embedded in paraffin and cut into $4 \mu \mathrm{m}$ slice by a rotary microtome. The sections were dewaxed and rehydrated using a graded alcohol series (100, 95, 90 and 80\%) and then applied for antigen retrieval (high pressure heating at $121^{\circ} \mathrm{C}$ in repair buffer for $3 \mathrm{~min}$ ). Afterwards, the sections were blocked with 10\% FBS and 1\% BSA (Sigma-Aldrich; Merck KGaA) TBS solution at room temperature for $2 \mathrm{~h}$ and incubated with THBS2 antibody (cat. no. ab112543; 1:500; Abcam) overnight at $4^{\circ} \mathrm{C}$. The sections were incubated with $0.3 \% \mathrm{H}_{2} \mathrm{O}_{2}$ at room temperature for $15 \mathrm{~min}$ and subsequently with the goat anti-rabbit secondary antibody (cat. no. ab7090; 1:300; Abcam) at room temperature for $1 \mathrm{~h}$. After colouration with 3,3-diaminobenzidin at room temperature without light for $10 \mathrm{~min}$, all sections were dehydrated, cleared, mounted and visualized using a light microscope (magnification, x100; Phenix Optics Co., Ltd.).

Chromatin immunoprecipitation- $q P C R(C h I P-q P C R)$. DNA and proteins of QGP-1 and BON-1 cells were crosslinked with $1 \%$ formaldehyde at room temperature for $20 \mathrm{~min}$, and then the complexes were sonicated on ice for $2 \mathrm{~min}$ ( $25 \%$ power; $4.5 \mathrm{sec}$ shock; 9 sec clearance; 14 times; Sonics and Materials, Inc.) to achieve 200-500 bp DNA fragments. DNA fragments bound by specific proteins were immunoprecipitated with immunoglobulin G (cat. no. sc-2025; 1:80; Santa Cruz Biotechnology, Inc.) or CUX1 antibodies (cat. no. sc-13024; 1:40; Santa Cruz Biotechnology, Inc.). Eluted DNA fragments were analyzed by semi-qPCR. MMP9 forward primer: 5'-CCAATCACCACC ATCCGTTG-3' and reverse primer: 5'-CCTCGGGCAAAT GTCTTACC-3'. The reaction conditions were as follows: Initial denaturation at $95^{\circ} \mathrm{C}$ for $3 \mathrm{~min}$, then 40 cycles of $95^{\circ} \mathrm{C}$ for $5 \mathrm{sec}$ and $58^{\circ} \mathrm{C}$ for $30 \mathrm{sec}$. Relative gene expression was analyzed by $2^{-\Delta \Delta \mathrm{Cq}}$ method (22) and normalized to the controls. The qPCR products were separated by a $2 \%$ agarose gel, stained by $10000 *$ SolarRed (Beijing Solarbio Science and Technology Co., Ltd.) and visualized using a Gel imaging analysis system (WD-9413B; Beijing Liuyi Biotechnology Co., Ltd.)
Statistical analysis. All statistical analyses were performed using SPSS software (version 17.0; SPSS, Inc.) and GraphPad Prism software (version 5.0; GraphPad Software, Inc.). Quantitative data were presented as mean \pm standard deviation. The statistical significance between two groups was calculated by Student's t-test. The significance of the difference between more than two groups was evaluated by one-way analysis of variance followed by Tukey's post hoc test. Linear correlation analyses were performed in order to determine correlations between THBS2 and miR-744-5p expression levels. $\mathrm{P}<0.05$ was considered to indicate a statistically significant difference.

\section{Results}

Altered levels of THBS2 in pancreatic neuroendocrine tumors (pNET). Using publicly available datasets (GSE73338) from the GEO database, it was revealed that THBS2 was significantly downregulated in pNET compared with normal tissues (Fig. 1A) (23). In addition, qPCR assay revealed that THBS2 expression in the 10 pNET samples was 2.6-fold less than that in para-carcinoma tissues (Fig. 1B). The expression levels of THBS2 in pNET specimen are presented in Fig. 1C. Consistently, pNET cell lines QGP-1 and BON-1 also exhibited decreased levels of THBS2 when compared with the 293 and human lung fibroblast CCL-153 cell lines (Fig. 1D).

THBS2 overexpression represses the proliferation and migration of pNET cells in vitro. The present study established THBS2 stable-overexpressed (OE) QGP-1 and BON-1 cells in order to investigate the effect of THBS2 on pNET development. According to the qPCR results, OE group expressed $>100$ times more THBS2 compared with the NC group (data not shown). The western blotting results further verified the upregulation of THBS2 in THBS2 OE cells (Fig. 2A). In contrast to the NC group, THBS2 overexpression impaired the proliferative capacity of pNET cells, as demonstrated by the MTT and EdU assay (Fig. 2B-D). The migration abilities of THBS2-overexpressed cells also decreased markedly when compared with NC (Fig. 2E). These results indicated that THBS2 significantly inhibited the proliferation and migration of pNET cells.

THBS2 is regulated by miR-744-5p. Bioinformatics analysis using the TargetScan, miRTarBase, RegRNA2.0 and RNA22 database predicted that THBS2 mRNA was the downstream target of miR-744-5p (Fig. 3A). Furthermore, datasets from LinkedOmics databases demonstrated that the expression level of miR-744-5p was negatively correlated with THBS2 in pancreas-adenocarcinoma-other subtype (Fig. 3B). Therefore, the cross-regulation between THBS2 and miR-744-5p was assayed. First, it was revealed that miR-744-5p was upregulated in pNET (NCBI/GEO/GSE43796) (24) and pancreatic cancer samples. miR-744-5p was also upregulated in BON-1 and QGP-1 cells when compared with 293 cells (Fig. 3C) (21). The luciferase reporter assay was then performed. miR-744-5p cotransfection induced a significant decrease in the signal of the luciferase reporter containing THBS2 MRE, but not the mutant THBS2 MRE reporter, demonstrating that THBS2 was a direct target of miR-744-5p (Fig. 3D). In addition, miR-744-5p overexpression or interference inhibited or promoted THBS2 
A
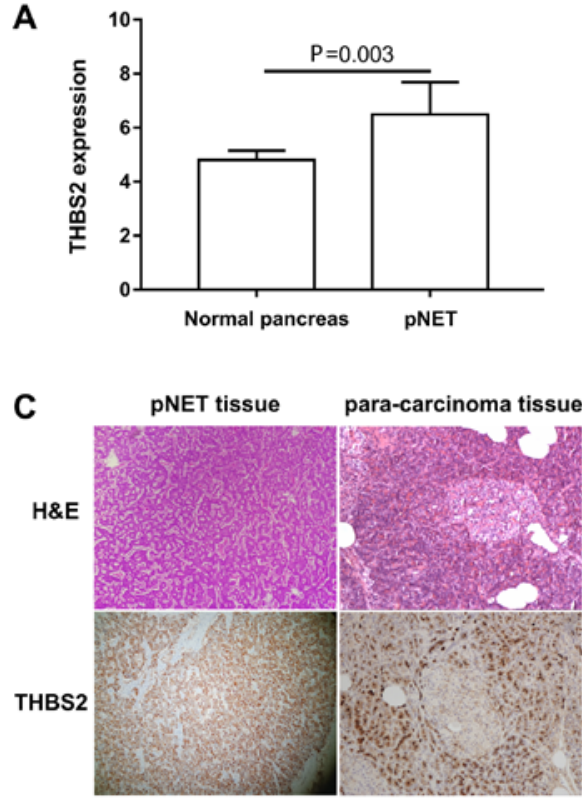

B

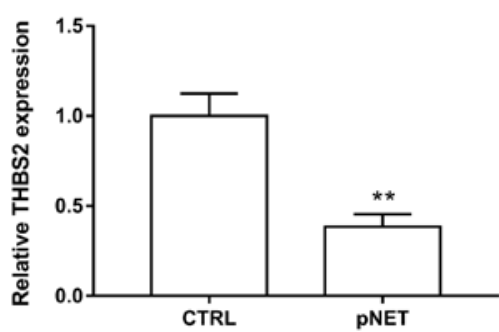

D

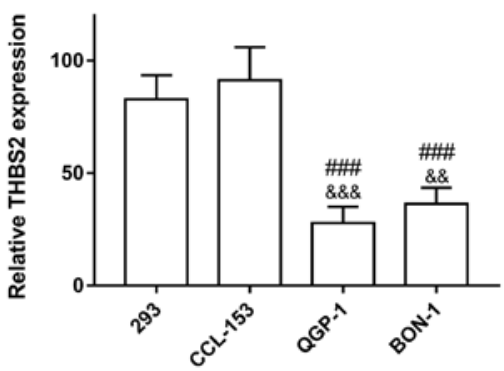

Figure 1. THBS2 is downregulated in pNET. (A) Gene Expression Omnibus dataset (GSE73338) analysis of THBS2 expression in pNET specimens compared to normal controls. (B) The expression of THBS2 in 10 pNET tissues and the paired para-carcinoma tissues were detected by qPCR. (C) Hematoxylin and eosin stain and immunohistochemistry stain of pNET and the paired para-carcinoma tissues Hematoxylin and eosin stain magnification, x40; immunohistochemistry stain magnification, x100. (D) The expression of THBS2 in pNET cell lines QGP-1 and BON-1 and normal human cell line 293 and CCL-153 were detected by qPCR. ${ }^{* *} \mathrm{P}<0.01$ vs. CTRL; ${ }^{\&} \mathrm{P}<0.01$ and ${ }^{\& \& \&} \mathrm{P}<0.001$ vs. 293 cells; ${ }^{* \# \#} \mathrm{P}<0.001$ vs. CCL-153 cells. THBS2, thrombospondin 2; pNET, pancreatic neuroendocrine tumor; qPCR, quantitative PCR; CTRL, control.

A

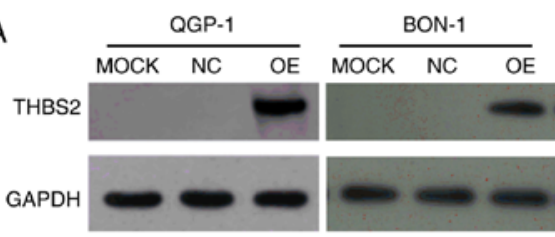

C

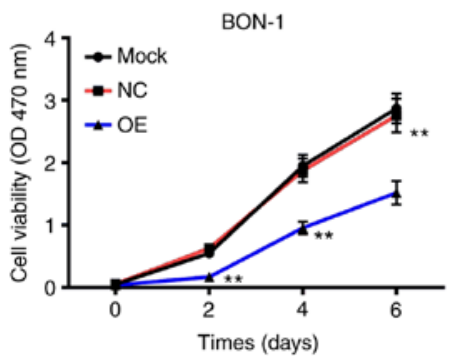

$E$

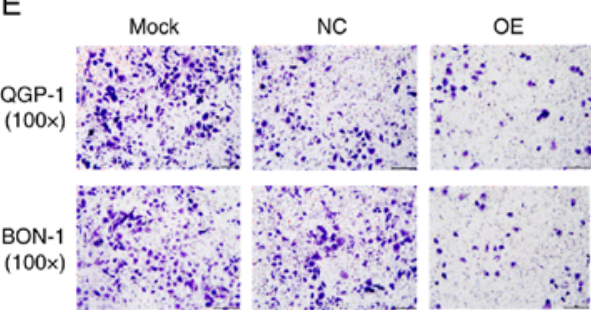

B

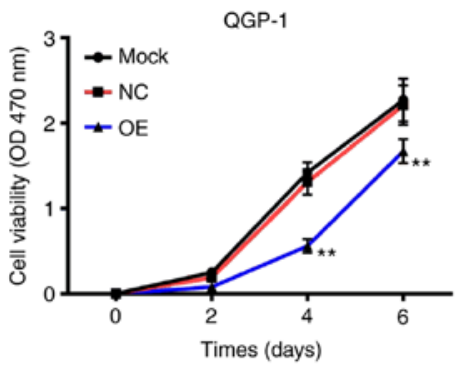

D

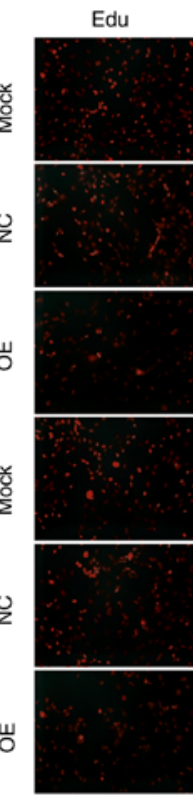

Hoechst

Merge
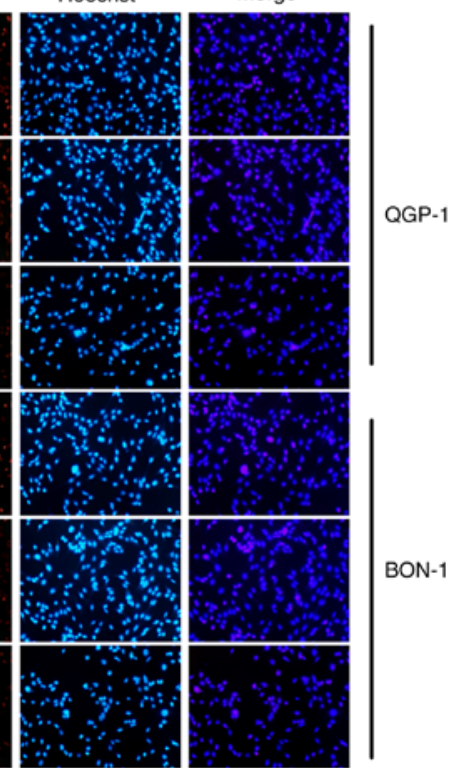

Figure 2. THBS2 overexpression repressed the proliferation and migration activity of pNET cells. (A) QGP-1 and BON-1 cells were stably transfected with THBS2 lentivirus or vector lentivirus. The transfection effect was verified by western blotting assay. (B) MTT assay of the MOCK, NC and OE groups in QGP-1 cells after 2, 4 or 6 days of culture. (C) MTT assay of the MOCK, NC and OE groups in BON-1 cells after 2, 4 or 6 days of culture. (D) EdU assay of the MOCK, NC and OE groups in pNET cells after $24 \mathrm{~h}$ of culture. (E) Transwell assay of the MOCK, NC and OE groups in pNET cells. **P $<0.01 \mathrm{vs.} \mathrm{NC.}$ THBS2, thrombospondin 2; OE, THBS2 lentivirus; $\mathrm{NC}$, negative control (vector lentivirus). 
A
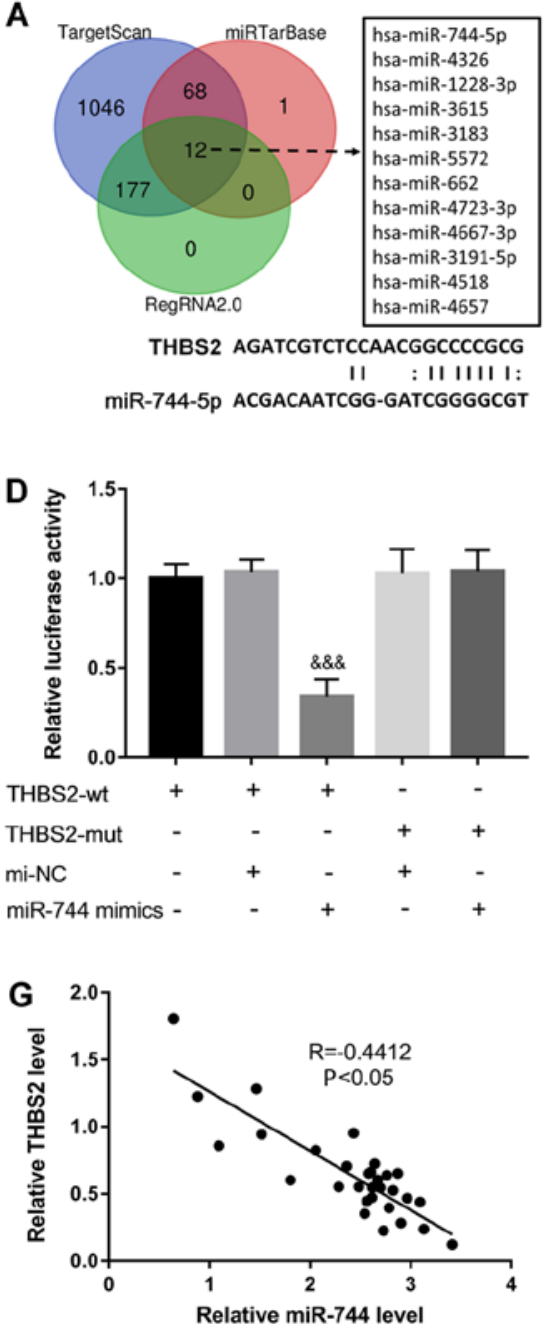

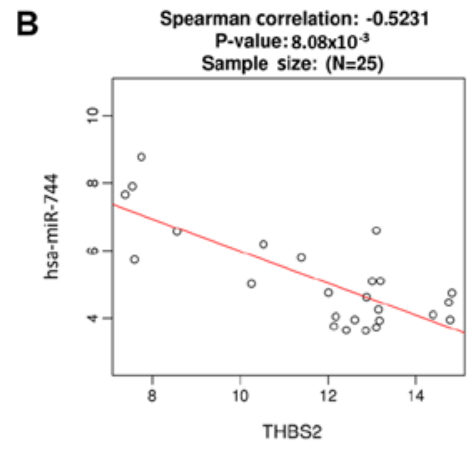

$\mathrm{E}$

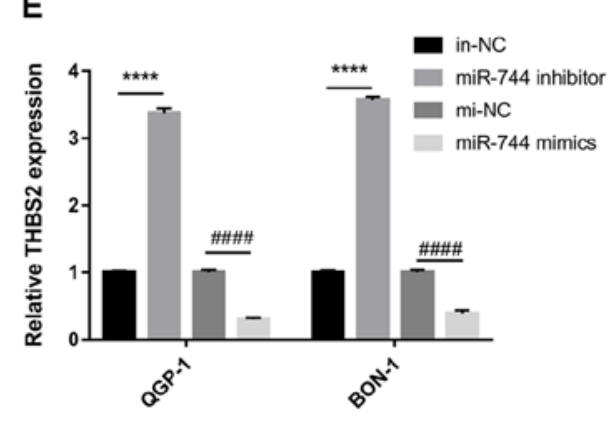

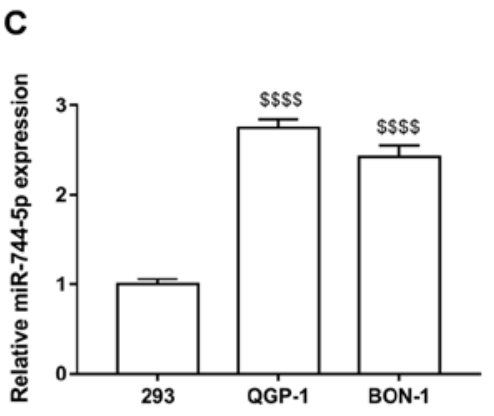

$\mathbf{F}$

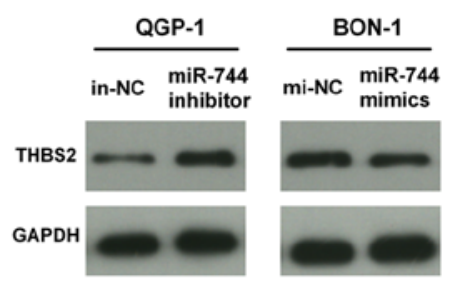

Figure 3. THBS2 was a direct target of miR-744-5p. (A) Venn diagram demonstrating that 12 genes are putative miR-744 targets predicted by TargetScan, miRTarBase and RegRNA2.0 database. (B) The correlation between miR-744-5p and THBS2 in pancreas-adenocarcinoma-other subtype from the LinkedOmics databases. (C) qPCR analysis of the expression of miR-744-5p in BON-1, QGP-1 and 293 cells. (D) Luciferase activity of wt THBS2 reporter and mutant THBS2 reporter constructs in 293 cells following transfection of miR-744-5p mimics. (E) qPCR and (F) western blot analysis the expression of THBS2 following transfection of miR-744-5p mimics or inhibitor. (G) The expression of THBS2 was negatively correlated with miR-744-5p in pNET tissues.

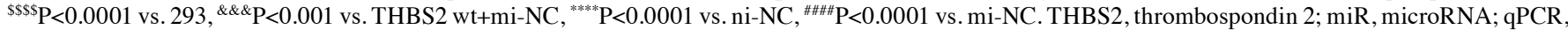
quantitative PCR; wt, wild-type; Mut, mutation; NC, negative control.

expression both at transcription and translation level in BON1 and QGP-1 cells, respectively (Fig. 3E and F). Furthermore, Pearson's correlation analysis revealed a negative correlation between miR-744-5p and THBS2 in 30 tumor tissues (Fig. 3G). These results indicated that upregulation of miR-744-5p led to the suppression of THBS2 in pNET.

THBS2 inhibits the CUX1/MMP9 axis. Thrombospondin/CD36 cascade regulated PAR2 signaling in microvascular endothelial cells (17). CUX1 was reported to be the downstream effector of PAR2 (18). Upregulated CUX1 also stimulated the expression of MMP9 in pNET. The present study thus predicted that THBS2 regulated MMP9 through CUX1 in pNET. First, the present study verified that CUX1 was a transactivator for MMP9 transcription using ChIP and luciferase reporter assays (Fig. 4A and B). The effect of THBS2 on CUX1 was then investigated. CUX1 levels did not change in either mRNA or protein levels when the expression of THBS2 was artificially changed in QGP-1 and BON-1 cells
(Fig. 4C and D). However, in the ChIP assay, the amount of CUX1 proteins bound to MMP9 fragments in THBS2 OE cells was lower compared with that in NC cells, implying that THBS2 may impair the interaction between CUX1 and the MMP9 promoter (Fig. 4E and F). Consistently, the transcription stimulation of CUX1 on MMP9 promoter was also decreased in THBS2 OE cells when compared with NC cells, validated by luciferase reporter assay (Fig. 4G and $\mathrm{H}$ ). Furthermore, THBS2 inhibited the expression of MMP9 at transcriptional level, whereas CUX1 overexpression alleviated this effect in QGP-1 cells (Fig. 4I and K). On the other hand, THBS2 interference stimulated the production of MMP9, which was counteracted by CUX1 knockdown in BON-1 cells, indicating that THBS2 regulated the production of MMP9 is CUX1-dependent (Fig. 4J and K).

THBS2/CUX1/MMP9 axis is critical for pNET cell proliferation and migration. The present study assessed whether THBS2 repression promoted pNET cell proliferation and migration 
A

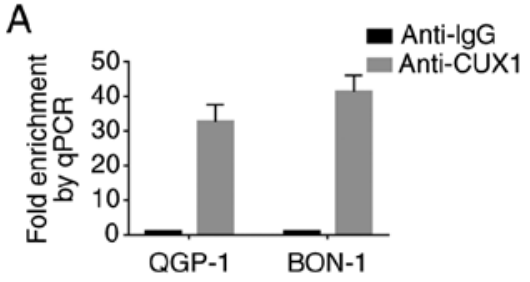

D

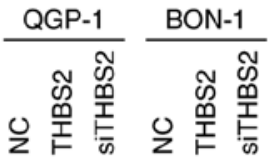

cux1 $=-0$

GAPDH
B

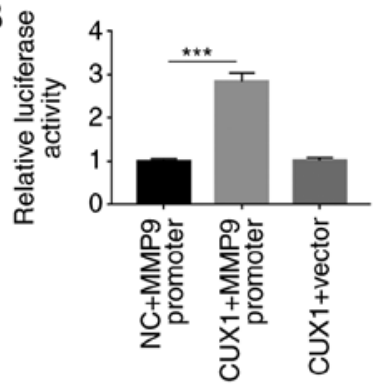

E
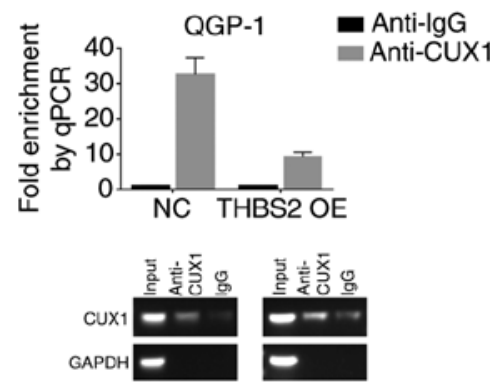

C
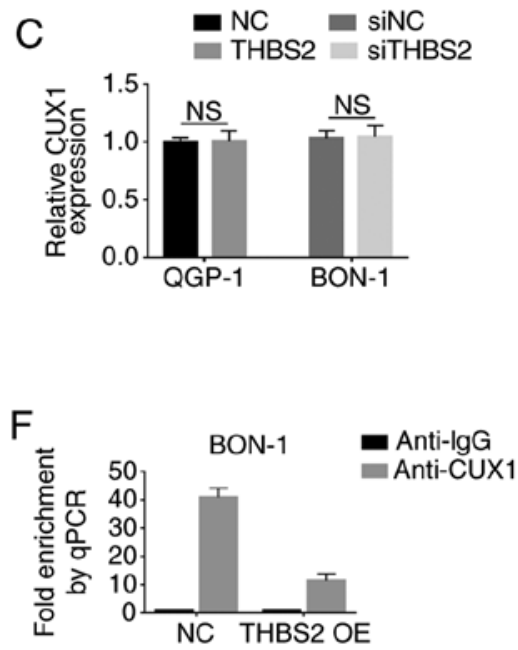
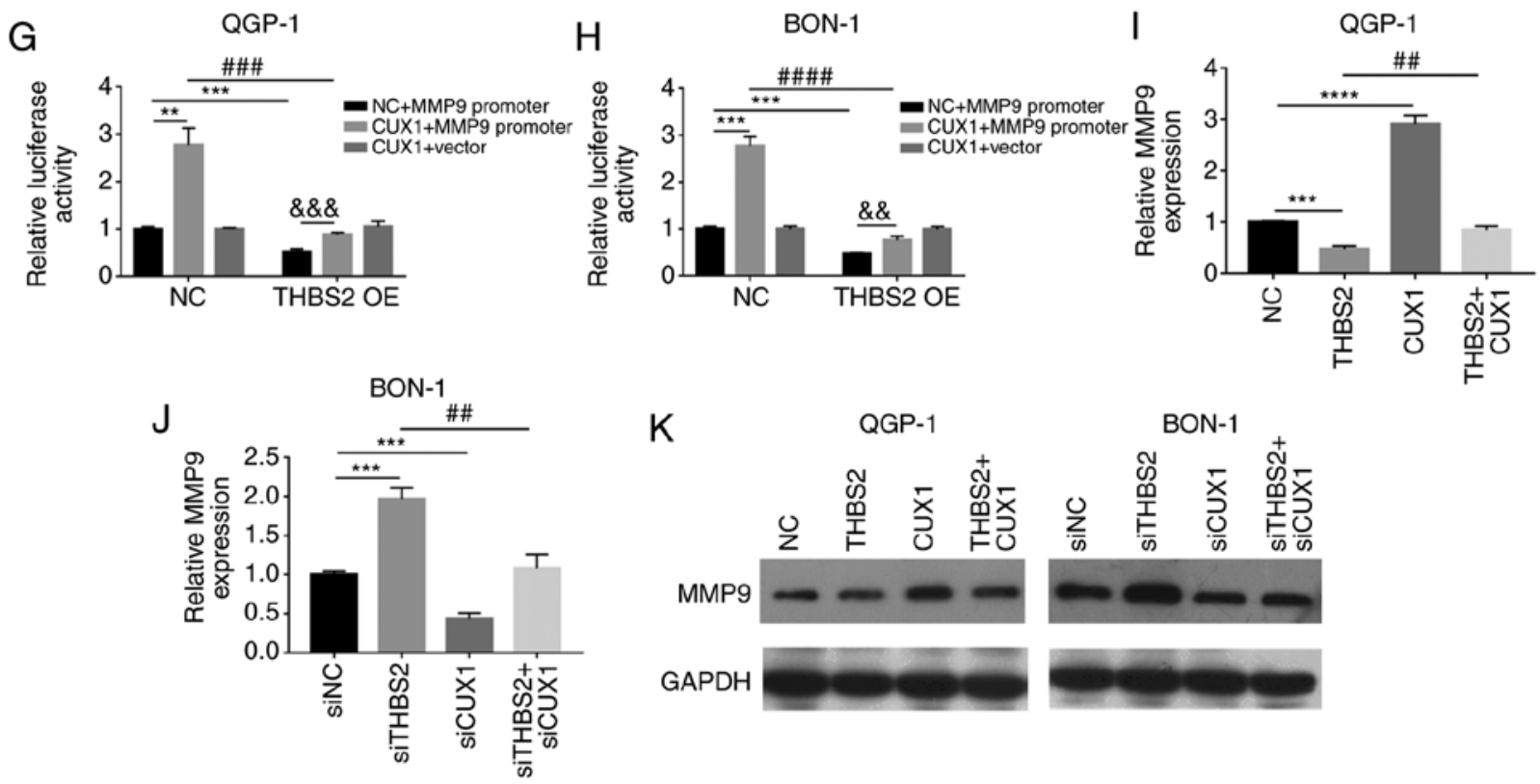

K

QGP-1

BON-1

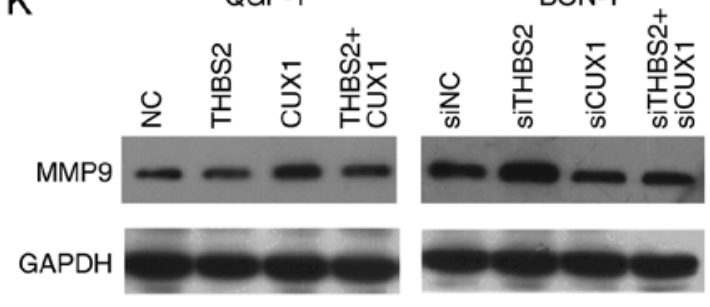

Figure 4. THBS2 regulates the CUX1/MMP9 cascade. (A) CUX1 directly interacted with the MMP9 promoter. qPCR analysis following ChIP revealed enrichment of the MMP9 promoter sequence in the anti-CUX1-precipitated DNA compared with the IgG group. (B) Luciferase reporter analysis after 293 cells were co-transfected with plasmid, with or without CUX1 and reporter, with or without MMP9 promoter for $48 \mathrm{~h}$. (C) qPCR and (D) western blot analysis demonstrating the expression of CUX1 after THBS2 was overexpressed or knocked-down. (E and F) qPCR analysis of the MMP9 sequences bound with CUX1 after ChIP analysis in NC or (E) THBS2 OE QGP-1 and (F) BON-1 cells. (G and H) The relative luciferase activity was detected after NC or (G) THBS2 OE QGP-1 and (H) BON-1 cells were co-transfected with plasmid with or without CUX1 and reporter with or without MMP9 promoter for $48 \mathrm{~h}$. (I-K) MMP9 expression was detected by qPCR (I and J) and western blot $(\mathrm{K})$ after THBS2 or CUX1 was overexpressed or knockdown. ${ }^{* *} \mathrm{P}<0.01,{ }^{* * * *} \mathrm{P}<0.001$ or

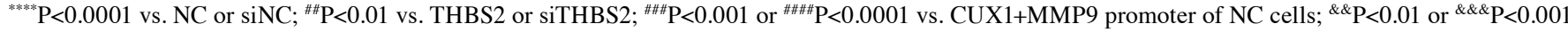
vs. NC of THBS2 OE cells. THBS2, thrombospondin 2; CUX1, CUT-like homeobox 1; MMP, matrix metalloproteinase; qPCR, quantitative PCR; OE, THBS2 lentivirus; NC, negative control; NS, not significant; si, small interfering.

through activating CUX1 and MMP9. As presented in the MTT and Transwell assay, CUX1 and MMP9 knockdown reversed downregulated THBS2-induced cell proliferation and migration in QGP-1 cells (Fig. 5A and C), respectively. On the contrary, CUX1 and MMP9 exogenous expression prevented the proliferation and migration repression caused by THBS2 upregulation in BON-1 cells (Fig. 5B and C), respectively. In summary, these data suggested that THBS2 downregulation stimulated the activity and expression of CUX1 and MMP9, respectively, which was associated with pNET development.

\section{Discussion}

In the present study, it was revealed that THBS2 was downregulated in pNET tissue and cells. Furthermore, THBS2 overexpression inhibited the proliferation and migration of 
A

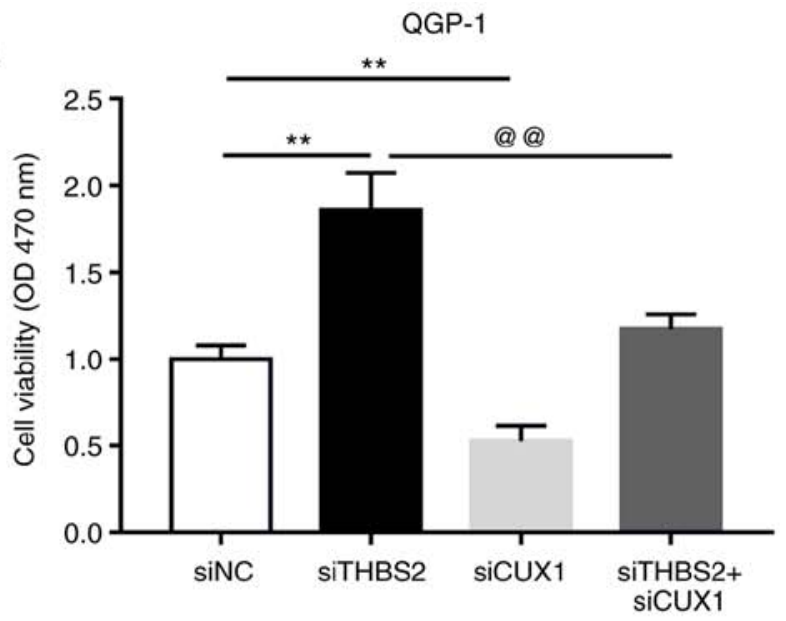

C

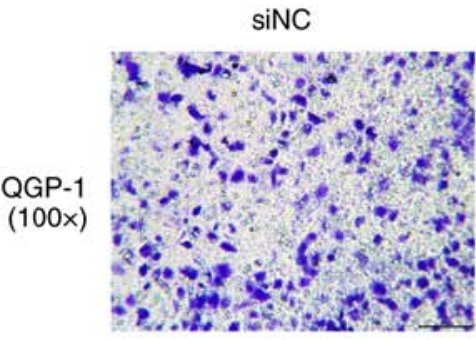

NC

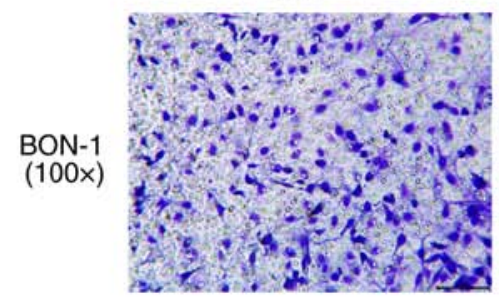

siTHBS2
B
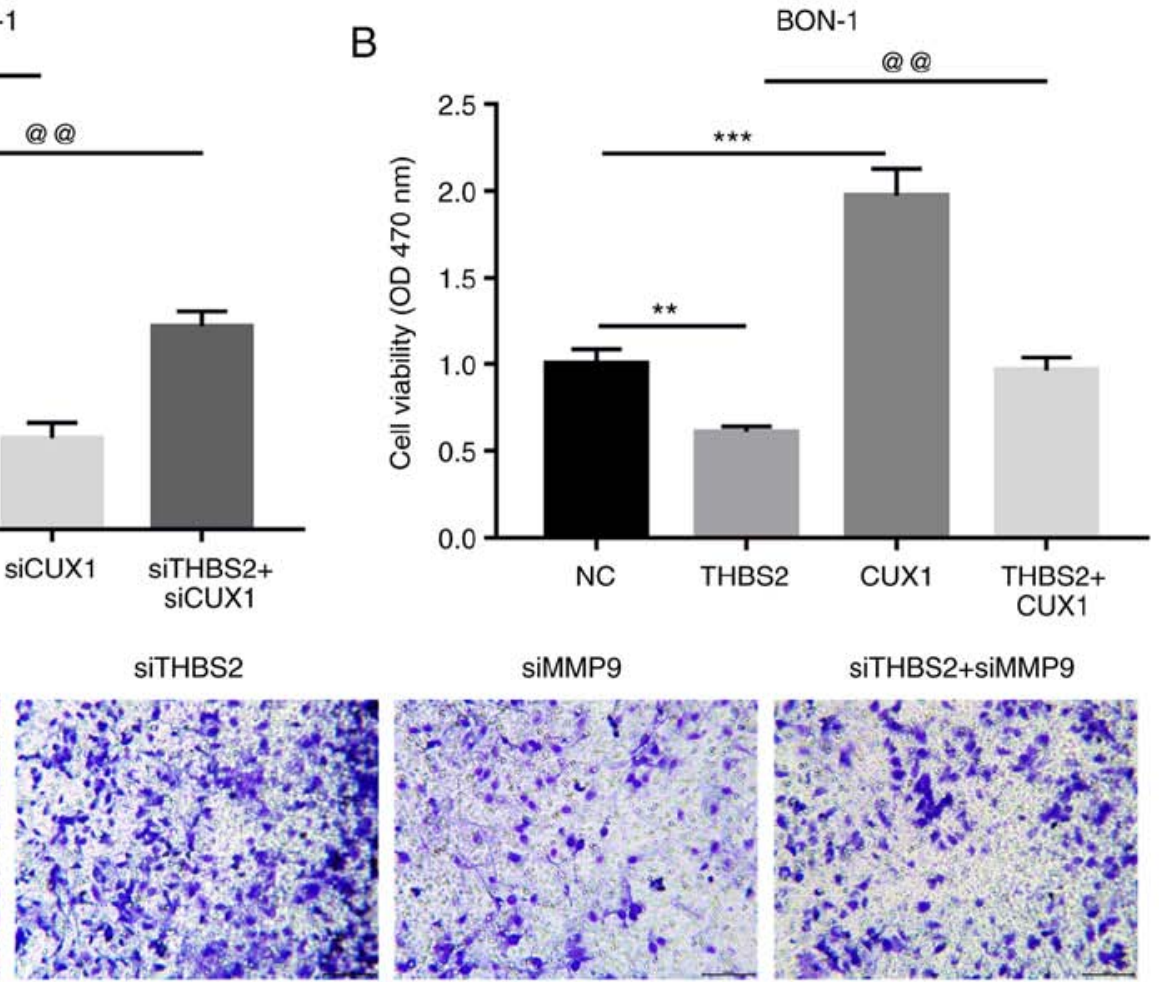

siTHBS2+siMMP9

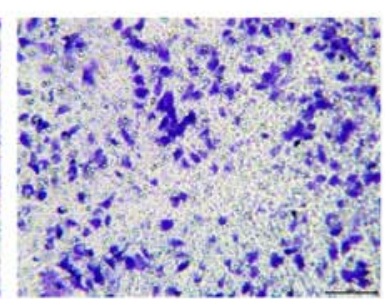

THBS2+MMP9

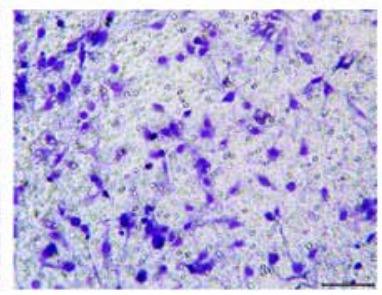

MMP9
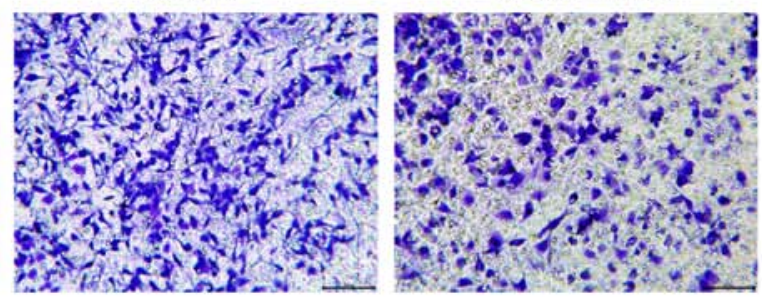

Figure 5. THBS2/CUX1/MMP9 axis affected pNET progression. Viability of (A) QGP-1 and (B) BON-1 cells following transfection with THBS2, CUX1, siTHBS2 and siCUX1 for 3 days. ${ }^{* * *} \mathrm{P}<0.01$ and ${ }^{* * * *} \mathrm{P}<0.001$ vs. NC or siNC; ${ }^{\circledR} \mathrm{P}<0.01$ vs. THBS2 or siTHBS2. (C) Transwell assays were performed in QGP-1 and BON-1 cells 24 h post-transfection. THBS2, thrombospondin 2; CUX1, CUT-like homeobox 1; MMP, matrix metalloproteinase; si, small interfering; NC, negative control.

pNET cells. Upregulation of miR-744-5p resulted in THBS2 repression. THBS2 could regulate MMP9 through affecting the transcriptional activity of CUX1. The THBS2/CUX1/MMP9 cascade modulated proliferation and migration in pNET.

THBS2 contains the type II repeats similar to epidermal growth factor repeats, the type III repeats for calcium binding, the thrombospondin common C-terminal domain for cell binding, as well as the THBS1 and THBS2 unique type I repeats used for interacting with TGF $\beta$, MMP9 and CD36 (13). Deregulation of THBS2 induces adhesion, apoptosis, migration and cytoskeletal organization of cancer cells (25). Chen et al (26) reported that THBS2 promoted prostate cancer bone metastasis by inducing miR-376c-mediated MMP2 upregulation. Cancer-associated fibroblasts also suppressed prostate cancer invasion via modulation of the ER $\alpha /$ THBS2/MMP3 axis (27). THBS2 silencing inhibited gastric cancer progression through the PI3K/AKT signaling pathway (28). THBS2 potentiated Notch3/Jagged1 signaling, which decreased cancer cell proliferation (29). THBS2 repression receded the degradation of MMP9 and thus promoted VEGF production (13). In addition, THBS2 modulated a series of processes comprising chondrogenesis collagen fibrillogenesis, wound healing, angiogenesis, tumor growth and cell apoptosis $(10,30)$. The present study proved that downregulation of THBS2 induced proliferation of pNET cells through CUX1 and promoted migration through MMP9.

PI3K/AKT/NOS, Rac/ROS, CYP1B1/ROS, NF-кB, adrenocorticotrophic hormone-receptor and estrogen receptor $\alpha$ $(E R \alpha)$ signaling, as well as DNA methylation and miRNA deregulation, have all been reported as involved in the regulation of THBS2 expression (27,30-32). However, to the best of our knowledge, the regulators of THBS2 in pNET have not yet been investigated. The present study revealed that miR-744-5p targeted THBS2 transcripts directly, and that upregulation of miR-744-5p may induce THBS2 inhibition. Aberrant expression of miR-744-5p has been identified in a number of different types of cancer, which affected cancer progression by targeting different proteins, such as Bcl-2, cMyc, TGF- $\beta 1$, Notch1, PTP1B, PAX2, RING1, MAFG, NFIX and HNRNPC (33-38). miR-744-5p targeted SFRP1, GSK3 $\beta$ and TLE3 to modulate Wnt/ $\beta$-catenin signaling, which was associated with lymph node metastasis, recurrences, prognosis and chemoresistance in pancreatic cancer $(39,40)$. Furthermore, miR-744-3p stimulated 
MMP9 production via different ways in laryngeal squamous cell carcinoma (19), suggesting that miR-744 clustering may be a potent regulator of MMP9 as well as metastasis. Furthermore, transcription factor c-Jun, TLR4/NF- $\kappa \mathrm{B}$ signaling, DNA hypermethylated and T-cell intracellular antigen (TIA) were revealed to regulate the expression of miR-744-5p $(33,34,41)$. However, the factors that stimulate the upregulation of miR-744-5p in pNET remain unknown.

The function of CUX1 consists of tumor suppression (via promoting base excision repair and transcriptionally inhibiting the PI3K/AKT signaling pathway), as well as tumor promoting (via promoting cell cycle progression and cell proliferation, stimulating cell migration and invasion, inducing apoptosis resistance, modulating the tumor microenvironment, reinforcing spindle assembly checkpoints to promote bipolar mitosis, and accelerating oxidative DNA damage repair) $(42,43)$. Upregulation of CUX1 stimulated proliferation, tumor growth, resistance to apoptosis and angiogenesis in Pnet (8). In the present study, CUX1 functioned as a transactivator for MMP9 transcription and induced the proliferation of pNET cells (potentially through modulating the transcription of certain effectors, for example p21, FGF1, VAV2), which was consistent with previous studies (44-46).

In the present study, it was speculated that THBS2 inhibited CUX1 through PAR2, as calcium mobilization of PAR2 can be repressed by thrombospondin/CD36 signaling, and transcription activity of CUX1 can be stimulated by PAR2 by enhancing its DNA binding ability $(17,18)$. As demonstrated in the present study, THBS2 could not regulate the production of CUX1 transcripts or proteins. However, CUX1 bound much less MMP9 and indicated weaker transcriptional activity for MMP9 in THBS2 OE cells when compared with NE cells. These results indicated that THBS2 inhibited the transcriptional activity of CUX1 for MMP9, which was in accordance with previous studies. However, whether this effect was indeed mediated by PAR 2 requires further investigation. In addition, CUX1 prevented the affect of THBS2 change on proliferation, which suggested that CUX1 may be a crucial effector of THBS2.

MMP2/9 forms complexes with THBS2 to interact with LRP1 and gets degraded; however, THBS2 could also regulate MMPs indirectly (26). The results from the present study demonstrated that CUX1 mediated the effect of THBS2 on MMP9. Whether THBS2 can regulate MMP9 directly in pNET cells remains uncertain. According to the results of the present study, THBS2 should not regulate exogenous MMP9 expression through CUX1, as the MMP9 plasmid lacks CUX1 binding sequences. However, Fig. 5C demonstrates that THBS2 upregulation inhibited MMP9 overexpression-induced migration, implying that THBS2 also regulates MMP9 expression at post-transcriptional level. In addition, MMP9 may be the major prometastatic effector of THBS2 as MMP9 knockdown or overexpression almost completely prevented the affect of THBS2 up- or downregulation on migration, respectively. Thus, the results of the present study suggested that inhibition of CUX1 and MMP9 may be an effective method to prevent THBS2 repression-caused pNET development.

\section{Acknowledgements}

Not applicable.

\section{Funding}

The present study was funded by the National Natural Science Foundation of China (grant no. 81773068).

\section{Availability of data and materials}

The datasets generated and/or analyzed during the current study are available in the Gene Expression Omnibus, (https://www.ncbi.nlm.nih.gov/geo/), the miRTarBase (http://mirtarbase.mbc.nctu.edu.tw/php/search.php), the RegRNA2.0 (http://regrna2.mbc.nctu.edu.tw/detection.html), and the LinkedOmics (http://www.linkedomics.org/admin. php) repositories.

\section{Authors' contributions}

HJ and WL designed the study, and wrote and revised the manuscript. LZ, JZ and SY performed the study and analyzed the data. All authors read and approved the final manuscript.

\section{Ethics approval and consent to participate}

The present study was approved by the Ethics Committee of Zhongshan Hospital of Fudan University (Shanghai, China). All patients provided written informed consent prior to the study start.

\section{Patient consent for publication}

Not applicable.

\section{Competing interests}

The authors declare that they have no competing interests.

\section{References}

1. Franko J, Feng W, Yip L, Genovese E and Moser AJ: Non-functional neuroendocrine carcinoma of the pancreas: Incidence, tumor biology, and outcomes in 2,158 patients. J Gastrointest Surg 14: 541-548, 2010.

2. Batukbhai BDO and De Jesus-Acosta A: The molecular and clinical landscape of pancreatic neuroendocrine tumors. Pancreas 48: 9-21, 2019.

3. Batcher E, Madaj P and Gianoukakis AG: Pancreatic neuroendocrine tumors. Endocr Res 36: 35-43, 2017.

4. Stevenson M, Lines KE and Thakker RV: Molecular genetic studies of pancreatic neuroendocrine tumors: New therapeutic approaches. Endocrinol Metab Clin North Am 47: 525-548, 2018

5. Kessenbrock K, Plaks V and Werb Z: Matrix metalloproteinases: Regulators of the tumor microenvironment. Cell 141: 52-67, 2010.

6. Bauvois B: New facets of matrix metalloproteinases MMP-2 and MMP-9 as cell surface transducers: Outside-in signaling and relationship to tumor progression. Biochim Biophys Acta 1825: 29-36, 2012.

7. Shchors K, Nozawa H, Xu J, Rostker F, Swigart-Brown L, Evan G and Hanahan D: Increased invasiveness of MMP-9-deficient tumors in two mouse models of neuroendocrine tumorigenesis. Oncogene 32: 502-513, 2013.

8. Krug S, Kühnemuth B, Griesmann H, Neesse A, Mühlberg L, Boch M, Kortenhaus J, Fendrich V, Wiese D, Sipos B, et al: CUX1: A modulator of tumour aggressiveness in pancreatic neuroendocrine neoplasms. Endocr Relat Cancer 21: 879-890, 2014.

9. Lawler J: The functions of thrombospondin-1 and -2. Curr Opin Cell Biol 12: 634-640, 2000. 
10. Calabro NE, Kristofik NJ and Kyriakides TR: Thrombospondin-2 and extracellular matrix assembly. Biochim Biophys Acta 1840: 2396-2402, 2014.

11. MirFA,Contreras-RuizLandMasliS:Thrombospondin-1-dependent immune regulation by transforming growth factor- $\beta 2$-exposed antigen-presenting cells. Immunology 146: 547-556, 2015.

12. Yang Z, Strickland DK and Bornstein P: Extracellular matrix metalloproteinase 2 levels are regulated by the low density lipoprotein-related scavenger receptor and thrombospondin 2 . J Biol Chem 276: 8403-8408, 2001.

13. Lawler J and Detmar M: Tumor progression: The effects of thrombospondin-1 and -2. Int J Biochem Cell Biol 36: 1038-1045, 2004.

14. Koch M, Hussein F, Woeste A, Gründker C, Frontzek K, Emons G and Hawighorst T: CD36-mediated activation of endothelial cell apoptosis by an N-terminal recombinant fragment of thrombospondin-2 inhibits breast cancer growth and metastasis in vivo. Breast Cancer Res Treat 128: 337-346, 2011.

15. Farberov S and Meidan R: Functions and transcriptional regulation of thrombospondins and their interrelationship with fibroblast grow th factor-2 in bovine luteal cells. Biol Reprod 91: $58,2014$.

16. Lopes N, Gregg D, Vasudevan S, Hassanain H, Goldschmidt-Clermont $\mathrm{P}$ and Kovacic $\mathrm{H}$ : Thrombospondin 2 regulates cell proliferation induced by Rac1 redox-dependent signaling. Mol Cell Biol 23: 5401-5408, 2003.

17. Enenstein J, Gupta K, Vercellotti GM and Hebbel RP: Thrombin-stimulated calcium mobilization is inhibited by thrombospondin via CD36. Exp Cell Res 238: 465-471, 1998.

18. Wilson BJ, Harada R, LeDuy L, Hollenberg MD and Nepveu A: CUX1 transcription factor is a downstream effector of the proteinase-activated receptor 2 (PAR2). J Biol Chem 284: 36-45, 2009.

19. Zhou W, Li Y, Gou S, Xiong J, Wu H, Wang C, Yan H and Liu T: MiR-744 increases tumorigenicity of pancreatic cancer by activating Wnt/ $\beta$-catenin pathway. Oncotarget 6: 37557-37569, 2015

20. Fléjou JF: WHO Classification of digestive tumors: The fourth edition. Ann Pathol 31 (5 Suppl): S27-S31, 2011 (In French).

21. Zhang YY and Feng HM: MEG3 suppresses human pancreatic neuroendocrine tumor cells growth and metastasis by down-regulation of Mir-183. Cell Physiol Biochem 44: 345-356, 2017.

22. Livak KJ and Schmittgen TD: Analysis of relative gene expression data using real-time quantitative PCR and the 2(-Delta Delta C(T)) method. Methods 25: 402-408, 2001.

23. Sadanandam A, Wullschleger S, Lyssiotis CA, Grötzinger C, Barbi S, Bersani S, Körner J, Wafy I, Mafficini A, Lawlor RT, et al: A cross-species analysis in pancreatic neuroendocrine tumors reveals molecular subtypes with distinctive clinical, metastatic, developmental, and metabolic characteristics. Cancer Discov 5: 1296-1313, 2015.

24. Park M, Kim M, Hwang D, Park M, Kim WK, Kim SK, Shin J, Park ES, Kang CM, Paik YK and Kim H: Characterization of gene expression and activated signaling pathways in solid-pseudopapillary neoplasm of pancreas. Mod Pathol 27: 580-593, 2014.

25. Nezu Y, Hagiwara K, Yamamoto Y, Fujiwara T, Matsuo K, Yoshida A, Kawai A, Saito T and Ochiya T: miR-135b, a key regulator of malignancy, is linked to poor prognosis in human myxoid liposarcoma. Oncogene 35: 6177-6188, 2016.

26. Chen PC, Tang CH, Lin LW, Tsai CH, Chu CY, Lin TH and Huang YL: Thrombospondin-2 promotes prostate cancer bone metastasis by the up-regulation of matrix metalloproteinase- 2 through down-regulating miR-376c expression. J Hematol Oncol 10: 33, 2017.

27. Slavin S, Yeh CR, Da J, Yu S, Miyamoto H, Messing EM, Guancial E and Yeh S: Estrogen receptor alpha in cancer-associated fibroblasts suppresses prostate cancer invasion via modulation of thrombospondin 2 and matrix metalloproteinase 3. Carcinogenesis 35: 1301-1309, 2014.

28. Ao R, Guan L, Wang Y and Wang JN: Silencing of COL1A2, COL6A3, and THBS2 inhibits gastric cancer cell proliferation, migration, and invasion while promoting apoptosis through the PI3k-Akt signaling pathway. J Cell Biochem 119: 4420-4434, 2018.

29. Meng H, Zhang X, Hankenson KD and Wang MM: Thrombospondin 2 potentiates notch3/jagged1 signaling. J Biol Chem 284: 7866-7874, 2009.
30. Zhou Q, Dong J, Luo R, Zhou X, Wang J and Chen F: MicroRNA-20a regulates cell proliferation, apoptosis and autophagy by targeting thrombospondin 2 in cervical cancer. Eur J Pharmacol 844: 102-109, 2019.

31. MacLauchlan S, Yu J, Parrish M, Asoulin TA, Schleicher M, Krady MM, Zeng J, Huang PL, Sessa WC and Kyriakides TR: Endothelial nitric oxide synthase controls the expression of the angiogenesis inhibitor thrombospondin 2. Proc Natl Acad Sci USA 108: E1137-E1145, 2011.

32. De Stefano D, Nicolaus G, Maiuri MC, Cipolletta D, Galluzzi L, Cinelli MP, Tajana G, Iuvone T and Carnuccio R: NF-kappaB blockade upregulates Bax, TSP-1, and TSP-2 expression in rat granulation tissue. J Mol Med (Berl) 87: 481-492, 2009.

33. Hatakeyama H, Nishizawa M, Nakagawa A, Nakano S, Kigoshi T, Miyamori I and Uchida K: Thrombospondin expression in aldosterone-producing adenomas. Hypertens Res 25: 523-527, 2002.

34. Sha Z, Zhu X, Li N, Li Y and Li D: Proto-oncogenic miR-744 is upregulated by transcription factor c-Jun via a promoter activation mechanism. Oncotarget 7: 64977-64986, 2016.

35. Sánchez-Jiménez C, Carrascoso I, Barrero J and Izquierdo JM: Identification of a set of miRNAs differentially expressed in transiently TIA-depleted HeLa cells by genome-wide profiling. BMC Mol Biol 14: 4, 2013.

36. Chen S, Shi F, Zhang W, Zhou Y and Huang J: miR-744-5p inhibits non-small cell lung cancer proliferation and invasion by directly targeting PAX2. Technol Cancer Res Treat 18: 1533033819876913 , 2019.

37. Sui Y, Lin G, Zheng Y and Huang W: LncRNA MAFG-AS1 boosts the proliferation of lung adenocarcinoma cells via regulating miR-744-5p/MAFG axis. Eur J Pharmacol 859: 172465, 2019.

38. Kleemann M, Schneider H, Unger K, Sander P, Schneider EM, Fischer-Posovszky P, Handrick R and Otte K: MiR-744-5p inducing cell death by directly targeting HNRNPC and NFIX in ovarian cancer cells. Sci Rep 8: 9020, 2018.

39. Ching T, Song MA, Tiirikainen M, Molnar J, Berry M, Towner D and Garmire L: Genome-wide hypermethylation coupled with promoter hypomethylation in the chorioamniotic membranes of early onset pre-eclampsia. Mol Hum Reprod 20: 885-904, 2014.

40. Miyamae M, Komatsu S, Ichikawa D, Kawaguchi T, Hirajima S, Okajima W, Ohashi T, Imamura T, Konishi H, Shiozaki A, et al: Plasma microRNA profiles: Identification of miR-744 as a novel diagnostic and prognostic biomarker in pancreatic cancer. $\mathrm{Br} \mathrm{J}$ Cancer 113: 1467-1476, 2015.

41. Yang JC, Wu SC, Rau CS, Chen YC, Lu TH, Wu YC, Tzeng SL, Wu CJ and Hsieh CH: TLR4/NF- $\kappa$ B-responsive microRNAs and their potential target genes: A mouse model of skeletal muscle ischemia-reperfusion injury. Biomed Res Int 2015: 410721, 2015.

42. Ramdzan ZM and Nepveu A: CUX1: A haploinsufficient tumour suppressor gene overexpressed in advanced cancers. Nat Rev Cancer 14: 673-682, 2014

43. Hulea L and Nepveu A: CUX1 transcription factors: From biochemical activities and cell-based assays to mouse models and human diseases. Gene 497: 18-26, 2012.

44. Paul BM, Vassmer D, Taylor A, Magenheimer L, Carlton CG, Piontek KB, Germino GG and Vanden Heuvel GB: Ectopic expression of $\mathrm{Cux} 1$ is associated with reduced $\mathrm{p} 27$ expression and increased apoptosis during late stage cyst progression upon inactivation of Pkd1 in collecting ducts. Dev Dyn 240: 1493-1501, 2011.

45. Latreille R, Servant R, Darsigny M, Marcoux S, Jones C, Perreault $\mathrm{N}$ and Boudreau F: Transcription factor CUX1 is required for intestinal epithelial wound healing and targets the VAV2-RAC1 signalling complex. Biochim Biophys Acta Mol Cell Res 1864: 2347-2355, 2017.

46. Chen J, Zhou Z, Yao Y, Dai J, Zhou D, Wang L and Zhang QQ: Dipalmitoylphosphatidic acid inhibits breast cancer growth by suppressing angiogenesis via inhibition of the CUX1/FGF1/HGF signalling pathway. J Cell Mol Med 22: 4760-4770, 2018.

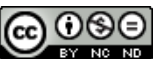

This work is licensed under a Creative Commons Attribution-NonCommercial-NoDerivatives 4.0 International (CC BY-NC-ND 4.0) License. 